\title{
PENINGKATAN LAYANAN SISTEM INFORMASI AKADEMIK BERBASIS ANDROID (STUDI KASUS DI STTA YOGYAKARTA)
}

\author{
Akbar Maulana Tirta ${ }^{1}$, Sumarsono ${ }^{2}$, Anton Setiawan Honggowibowo ${ }^{3}$ \\ ${ }^{13}$ Teknik Informatika STTA Yogyakarta \\ 2Universitas Negeri Islam Sunan Kalijogo Yogyakarta
}

\begin{abstract}
Academic information systems have a goal for facilitate students in to access there are information. But facilities which has given by college not yet maximum. With utilize smartphone based on android, students can be access there are Academic information systems. Client Server becomes solution method for implement Academic information systems to the smartphone.

This Academic information systems use database PostgreesSQL, it which implanted in server and become smartphone android have been installed Academic information systems application, it's become client.

Academic information systems application have many feature among other input KRS, view course value, view attendance and course schedule, with there are feature it, so will increase Academic information systems service.
\end{abstract}

Keywords: Academic Information Systems, Android

\begin{abstract}
Abstrak
Sistem informasi akademik memiliki tujuan untuk mempermudah mahasiswa dalam mengakses informasi yang ada. Tetapi fasilitas yang diberikan kampus belum maksimal. Dengan memanfaatkan smartphone berbasis android mahasiswa dapat mengakses sistem informasi akademik yang ada. Client server menjadi metode solusi untuk mengimplementasikan sistem informasi akademik ke dalam smartphone.

Dari perancangan sistem informasi akademik ini menggunakan database Postgrees $S Q$ yang ditanamkan di server dan menjadikan smartphone android yang telah di install aplikasi sistem informasi akademik menjadi client.

Aplikasi sistem informasi akademik mempunyai banyak fitur antara lain input krs, melihat nilai matakuliah, melihat absensi dan jadwal matakuliah, dengan adanya fitur tersebut maka akan meningkatkan layanan sistem informasi akademik yang sudah ada.
\end{abstract}

Kata Kunci : Sistem Informasi Akademik, Android

\section{Pendahuluan}

Perkembangan jumlah mahasiswa di Sekolah Tinggi Teknologi Adisutjipto (STTA) tidak berbanding lurus dengan pengadaan fasilitas yang mendukung sistem akademik. Sehingga menyebabkan terganggunya sistem akademik yang berjalan. Khususnya jumlah komputer yang dinilai sangat kurang. Kekurangan jumlah komputer dapat dilihat dari panjangnya antrian saat pengisian Kartu Rencana Studi (KRS). 
Komputer kini sudah menjadi kebutuhan yang sangat penting dalam kehidupan seharihari manusia. Sedangkan perkembangan komputer saat ini sangat maju, hal itu dapat dilihat dengan perkembangan ukuran komputer yang semakin kecil. Tidak itu saja komputer saat ini dapat digunakan di mana saja seperti halnya handphone. Smartphone adalah teknologi yang memadukan fungsi dari komputer dengan handphone. Dengan adanya smartphone manusia dapat menggunakan komputer dimana saja, karena smartphone yang ukurannya kecil dan kerjanya sudah mendekati notebook.

Dengan memanfaakan perkembangan teknologi khususnya smartphone maka diharapkan dapat menjadi solusi dalam keterbatasan jumlah komputer yang ada di STTA, sehingga para pelaksana sistem informasi akademik khususnya Mahasiswa dapat memanfaatkan sistem informasi akademik yang ada. Smartphone juga memungkinkan Mahasiswa untuk melakukan akses ke sistem informasi akademik dimana saja dan tentunya pada saat pengisian KRS yang membutuhkan komputer yang tidak sedikit agar tidak terjadi antrian maka dengan adanya sistem informasi akademik yang sudah dapat di akses dengan smartphone dapat mengurangi jumlah antrian tersebut.

Hal inilah yang membuat munculnya ide untuk menciptakan aplikasi sistem informasi akademik yang dapat berjalan di dalam smartphone, sehingga dapat meningkatan layanan sistem informasi akademik STTA Yogyakarta.

\section{Android}

Android (Menurut Nazruddin Safaat H, 2010) adalah sebuah sistem operasi untuk perangkat mobile berbasis linux yang mencakup sistem operasi, middleware dan aplikasi. Android menyediakan platform yang terbuka bagi para pengembang untuk menciptakan aplikasinya.

\subsection{PostgreSQL}

PostgreSQL merupakan DMS Server Open Source (Menurut Suswanto Raharjo, 2003). PostgreSQL memberikan dukungan untuk object Relational (ORDBMS) dan didukung oleh sebuah team pengembang yang melakukan pekerjaannya dengan komunikasi lewat internet. PostgreSQL merupakan turunan Open Source dari kode asli. PostgreSQL merupakan salah satu sistem database server yang dapat diinteraksikan dengan halaman platform melalui berbagai acara. Salah satunya adalah dengan menggunakan modul PHP dalam Apache platform server. Namun penggunaan sistem database server seperti PostgreSQL yang diinteraksikan dengan platform juga menimbulkan berbagai masalah. Salah satunya adalah masalah keamanan situs platform dan sistem database-nya. Oleh sebab itu masalah keamanan database menjadi suatu hal yang pokok dalam sistem database dan administrasinya. PostgreSQL, Apache dan PHP merupakan perangkat lunak yang bersifat Open Source, yang berarti bahwa kode sumber dari PostgreSQL, Apache dan PHP dapat digunakan secara bebas.

\subsection{PHP (Personal Home Page)}

PHP merupakan bahasa berbentuk script yang ditempatkan dalam server dan diproses di server (Menurut Wahana Komputer, 2010). PHP dirancang untuk membentuk aplikasi platform dinamis, artinya $P H P$ dapat membentuk suatu tampilan berdasarkan permintaan terkini. Pada prinsipnya PHP mempunyai fungsi yang sama dengan script seperti ASP (Active Server Page), Cold Fusion, atau pun Perl. 
Kode PHP diawali dengan tanda <? PHP dan diakhiri dengan?>. Pasangan kedua kode inilah yang berfungsi sebagai tag kode PHP. Berdasarkan tag inilah, pihak server dapat memahami kode PHP dan kemudian memprosesnya. Hasilnya dikirim ke browser atau microbrowser.

\subsection{Socket}

Socket adalah suatu abtraksi yang mana aplikasi dapat mengirim dan menerima data seperti sama halnya dengan membuka suatu file untuk dibaca dan ditulis pada tempat penyimpanan file (Menurut Agus Kurniawan, 2011). Socket memungkinkan untuk masuk ke dalam jaringan dan berkomunikasi dengan aplikasi lain yang juga masuk kedalam jaringan yang sama. Informasi yang ditulis kedalam socket pada suatu aplikasi pada suatu mesin dapat dibaca oleh aplikasi lain pada mesin yang berbeda dan sebaliknya.

Socket dapat bekerja di banyak protokol dan ilustrasi bagaimana socket berkomunikasi satu dengan lainnya. Ilustrasi komunikasi socket dapat dilihat pada gambar 1

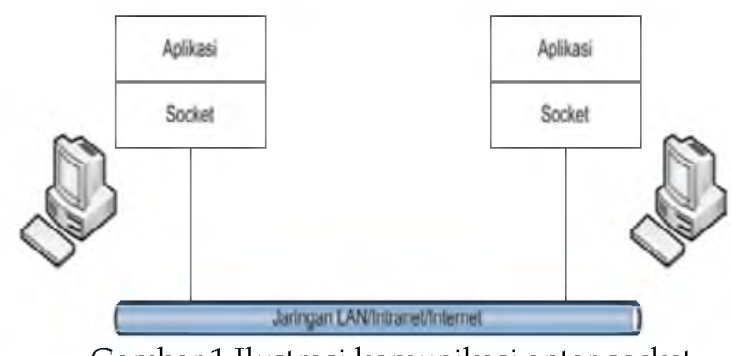

\section{$2.4 \mathrm{~J} 2 \mathrm{ME}$}

J2ME adalah teknologi Java yang diperuntukkan perangkat-perangkat kecil consumer device, terutama wireless. Beberapa perangkat wireless antara lain PC, PDA, communicator, embedded device, smart card dan ponsel. Teknologi Java mungkin merupakan satu-satunya cara memprogram beberapa perangkat, berbagi logic antara perangkat dan server, pengantaran aplikasi secara dinamis, program yang kompak, lingkungan pengembangan yang aman dan cepat. J2ME memungkinkan perangkat lunak dapat di-download perangkat sekaligus memungkinkan layanan yang dapat disesuaikan di beragam perangkat.

\subsection{ECLIPSE}

Eclipse merupakan open source, dan NetBeans, Sun ONE Studio dan Borland JBuilder perkembangan yang sama platform berbasis Java extensible terpadu, saat ini salah satu proyek sumber terbuka yang paling terkenal, IBM telah dalam beberapa tahun terakhir. Dalam dukungan kuat dari pengembangan proyek, tujuannya adalah untuk membuat alternatif untuk IBM Visual Age Java (disebut sebagai IVJ) generasi mendatang IDE lingkungan pengembangan, dan pada bulan November 2001 mengumumkan bahwa 4 juta dolar diinvestasikan ke dalam penelitian proyek dan pengembangan. Sendiri, hanya sebuah kerangka dan satu set layanan untuk membangun lingkungan pengembangan dengan plug-in komponen. Eclipse dilengkapi dengan plug standar, termasuk alat-alat pengembangan Java (Java Development Tools, JDT). Tujuan masa depan bukan hanya sebuah program khusus yang dikembangkan lingkungan Java IDE, berdasarkan arsitektur Eclipse, melalui pengembangan plug-in, dapat diperpanjang dengan perkembangan bahasa apapun, dan bahkan menjadi alat untuk menggambar gambar. 


\section{Perancangan Sistem}

\subsection{Spesifikasi Hardware dan Software}

Spesifikasi hardware dan software untuk perancangan aplikasi ini terdiri dari beberapa macam yaitu:

\subsubsection{Spesifikasi Hardware}

Hardware atau Perangkat keras merupakan peralatan fisik yang ada di komputer. Sistem perangkat keras ini terdiri unit input, proses, dan output. Berapa kebutuhan perangkat keras minimum yang digunakan dalam pembuatan sistem ini adalah :

1. Processor Intel Pentium Atom

2. Ram 2 GB

3. Harddisk $80 \mathrm{~GB}$

4. Android Phone Samsung Galaxi Mini

\subsubsection{Spesifkasi Software}

Software merupakan hal utama yang harus ada pada komputer, karena software berfungsi untuk mengontrol dan memanajemen hardware yang ada. Dari pembuatan aplikasi SIA berbasis android membutuhkan spesifikasi minimum diantaranya :

1. Ubuntu 11.04

2. PostgreeSQL 8.3

3. Phppgadmin

4. Froyo 2.2

5. Eclipse Helios

\subsection{Perancangan Sistem}

Sistem yang berjalan saat ini menggunakan aplikasi desktop dan website sebagai pengakses sistem informasi akademik di STTA. Sedangkan sistem yang akan dibangun berbasis android yang dapat mempermudah mahasiswa dalam pengisian krs, melihat nilai, melihat jadwal dan absensi. Dengan menanamkan aplikasi sistem informasi akademik ke dalam smartphone android yang sedang terkoneksi internet mahasiswa dapat mengakses sistem akademik tersebut.

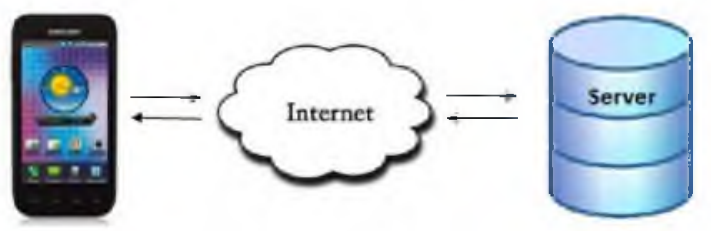

Gambar 2 Konfigurasi sistem 


\subsection{Analisa Kebutuhan Sistem}

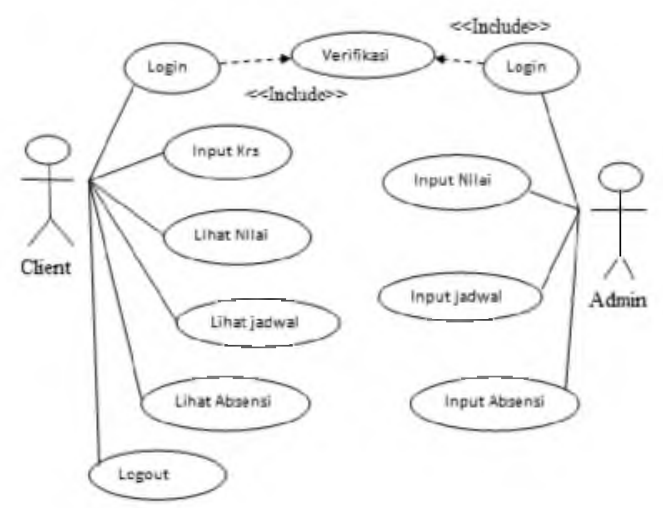

Gambar 3 Diagram use case

Pada saat aplikasi dijalan akan tampil form login yang meminta nim dan password mahasiswa. Jika berhasil akan ke form selanjutnya yaitu form menu aplikasi. Menu yang tersedia diantaranya input krs, melihat nilai, melihat jadwal dan melihat absensi. Setiap menu yang terpilih akan memanggil server sebagai pusat penyimpanan.

\section{Implementasi Sistem}

Untuk dapat menggunakan aplikasi SIA ini diperlukan smartphone berbasis android yang terhubung dangan internet sehingga dapat mengakses database STTA. Setelah terpenuhi itu semua maka mahasiswa dapat memanfaatkan fitur yang ada, antara lain :

1. Form login

Halaman ini digunakan mahasiswa untuk mengakses aplikasi SIA.

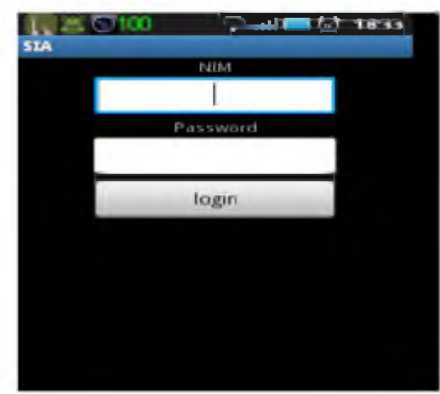

Gambar 4 Menu login

2. Menu Input Krs

Menu ini digunakan untuk menginputkan matakuliah yang ingin di pelajari saat semester aktif. 


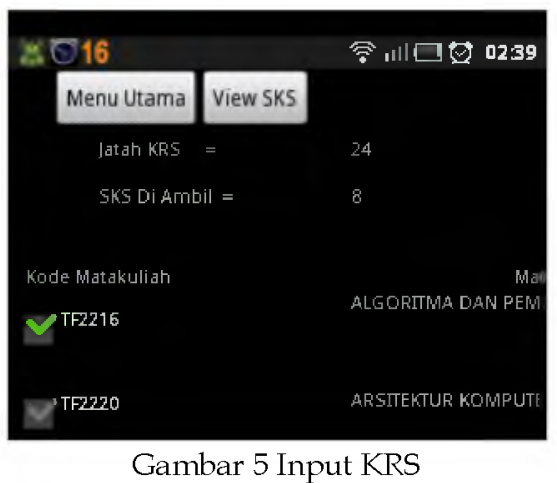

3. Menu Nilai

Menu ini digunakan untuk melihat nilai matakuliah yang telah terambil.

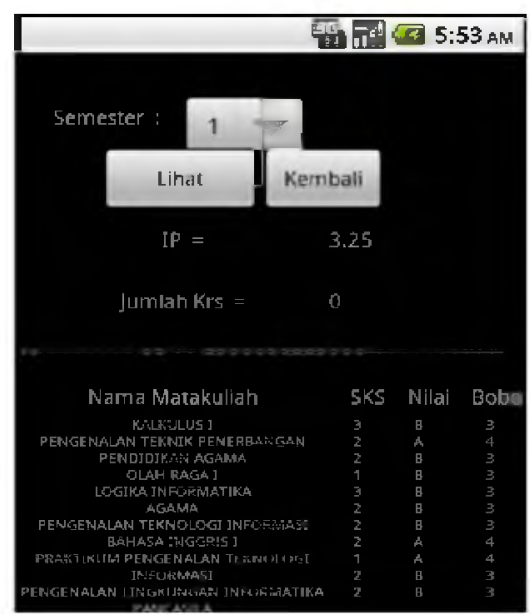

Gambar 6 Tampilan KRS

4. Menu Absensi

Menu ini digunakan untuk melihat absensi matakuliah yang telah diambil.

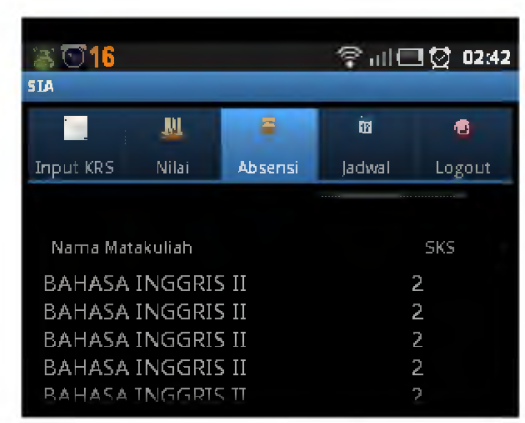

Gambar 7 Absensi matakuliah

5. Menu jadwal

Menu ini digunakan untuk melihat jadwal matakuliah. 


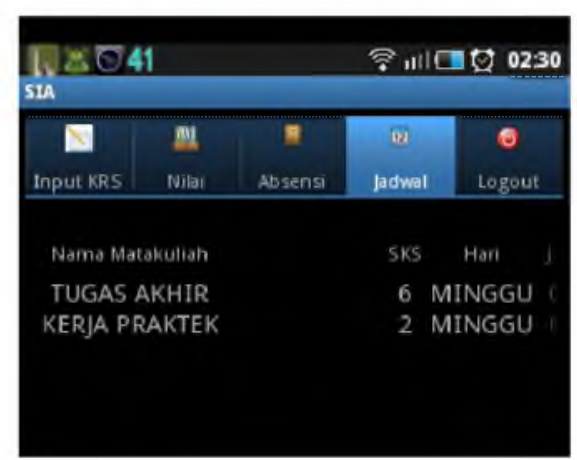

Gambar 8 Jadwal matakuliah

\section{Pengujian}

Pengujian sistem dilakukan dengan mengguanakan pengujian beta yang dilakukan secara objektif dimana diuji secara langsung ke lapangan dengan format kuesioner pada tabel 1 dan pengujian perbandingan kecepatan akses sistem yang dilakukan di Inherent STTA.

Tabel 1 Hasil Pengujian Beta

\begin{tabular}{|c|c|c|c|c|}
\hline \multirow[t]{2}{*}{ No. } & \multirow[t]{2}{*}{ Pertantaan } & \multicolumn{3}{|c|}{ Perijajan } \\
\hline & & Baik & Cukup & K'urang \\
\hline 1 & Tatupilan Aplikasi & 15 & 10 & 5 \\
\hline 2 & Kemudahan dalam Penggunaan & $\mathrm{LI}$ & 15 & 4 \\
\hline 3 & Kecepatan tuemproses data & 10 & 14 & 6 \\
\hline 4 & Keefisiensian penggunam memory & 18 & 12 & - \\
\hline 5 & Kemudahan dalam pengaksesan & 20 & 10 & - \\
\hline & Total & 74 & 61 & 15 \\
\hline & Persentase & $49,34,7$ & $40,6 \%$ & 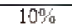 \\
\hline
\end{tabular}

Tabel 2 Hasil Pengujian Keceptan Akses

\begin{tabular}{|c|c|c|c|}
\hline No. & Jumlah Pengakses & Portal Akademik & SIA Android \\
\hline 1 & 5 & $24 \mathrm{~s}$ & $27 \mathrm{~s}$ \\
\hline 2 & 10 & $27 \mathrm{~s}$ & $30 \mathrm{~s}$ \\
\hline 3 & 15 & $30 \mathrm{~s}$ & $35 \mathrm{~s}$ \\
\hline 4 & 20 & $39 \mathrm{~s}$ & $42 \mathrm{~s}$ \\
\hline
\end{tabular}

\section{Kesimpulan}

Dari hasil uji aplikasi SIA ini dapat ditarik beberapa kesimpulan, yaitu. Smartphone android yang telah terinstal aplikasi SIA harus terkoneksi dengan internet agar dapat mengakses database di Inherent STTA yang menjadi tempat penyimpanan data sistem akademik dan aplikasi SIA ini dapat digunakan untuk melakukan proses input data KRS, melihat nilai, melihat jadwal kuliah dan melihat absensi matakuliah yang telah diambil sebelumnya. 


\section{Saran}

Dari kesimpulan diatas dapat dikemukakan beberapa saran dalam perkembangan aplikasi ini, antara lain :

1. Menambahkan fitur-fitur untuk pengajar seperti pengisian nilai dan menginputkan matakuliah yang disediakan per semester .

2. Aplikasi ini sebaiknya diimplementasikan dalam platform lainnya, seperti symbian dan Blackbery.

3. Pengembangan aplikasi ini sebaiknya disesuaikan dengan kemajuan hardware yang ada sehingga dapat meningkatkan kinerja aplikasi yang di gunakan.

\section{Referensi}

[1] Sihombing Evalin Marta Damayanti, Kusuma Guntur Prabawa dan Kusmayadi Hendra, Pembangunan Aplikasi Sistem Informasi Dosen Politeknik Telkom Pada Smartphone Berbasis Android, Bandung, 2011.

[2] Mulyadi, Membuat Aplikasi untuk Android, Multimedia Center Publishing, Yogyakarta, 2010.

[3] Raharjo, Suwanto, Keamanan Akses PostgreSQL Melalui PHP, Andi Offset, Yogyakarta, 2003.

[4] Melwin, Safrizal, Pengantar Jaringan Komputer, Andi Offset, Yogyakarta, 2005.

[5] Syafi, M., Panduan Membuat Aplikasi Database Dengan PHP 5 MySQL PostgreSQL Oracle, Andi Offset. Yogyakarta, 2006.

[6] Komputer Wahana, Paling Dicari PHP Source Code, Andi Offset. Yogyakarta, 2010.

[7] Saffat, Nazruddin, H., Pemrograman Aplikasi Mobile Smartphone dan Tablet PC Berbasis Android, Informatika, Bandung, 2010.

[8] Kurniawan, Agus, Dasar-Dasar Pemograman Socket dan Java, Andi Offset. Yogyakarta, 2011. 